\title{
Hemifacial spasm and neurovascular compression syndrome
}

Puya Dehgani Mobaraki, ${ }^{1,2}$ Ruggero Lapenna, ${ }^{1}$ Giampietro Ricci, ${ }^{1}$ Jacques Magnan ${ }^{3}$

${ }^{1}$ Section of Otorhinolaryngology, Department of Surgery and Biomedical Science, Universita degli Studi di Perugia, Perugia, Italy

${ }^{2}$ Association 'Naso Sano' Onlus, Umbria Regional Registry of Volunteer Activities, Corciano, Italy

${ }^{3}$ Laboratoire Otology Microendoscopy, Aix-Marseille University, Marseille Cedex, France

Correspondence to Dr Puya Dehgani Mobaraki, dehganipuya@gmail.com

Accepted 21 April 2017
CrossMark

To cite: Dehgani Mobaraki $P_{\text {, }}$ Lapenna R, Ricci G, et al. BMJ Case Rep Published Online First: [please include Day Month Year]. doi:10.1136/ bcr-2016-218883

\section{DESCRIPTION}

A 49-year-old woman experienced left orbicularis oculi muscle spasms for 16 months. The first 5 months were characterised by rare involuntary spasms, became stronger at any physical or mental activity and later they even occurred while the

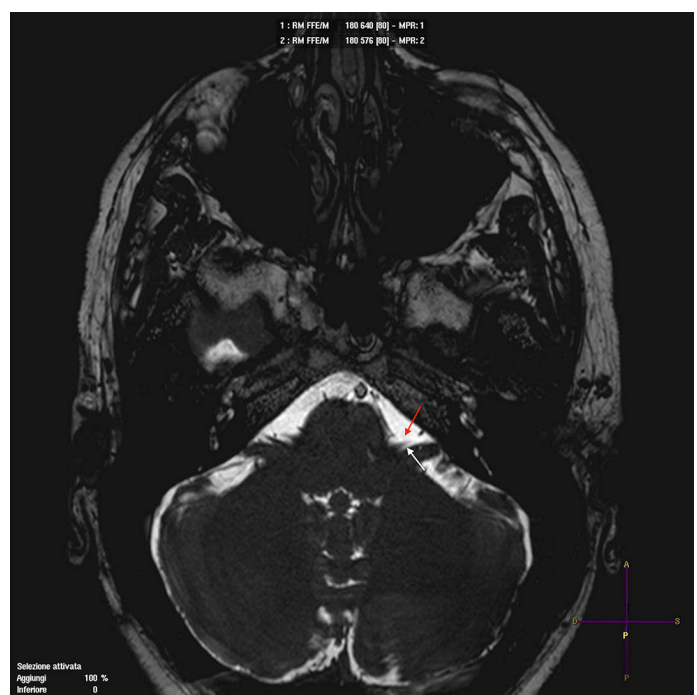

Figure 1 Preoperative 3T MRI: highly T2-weighted sequences for cisternography. Red arrow: anterior inferior cerebellar artery loop. White arrow: facial nerve at root exit zone.

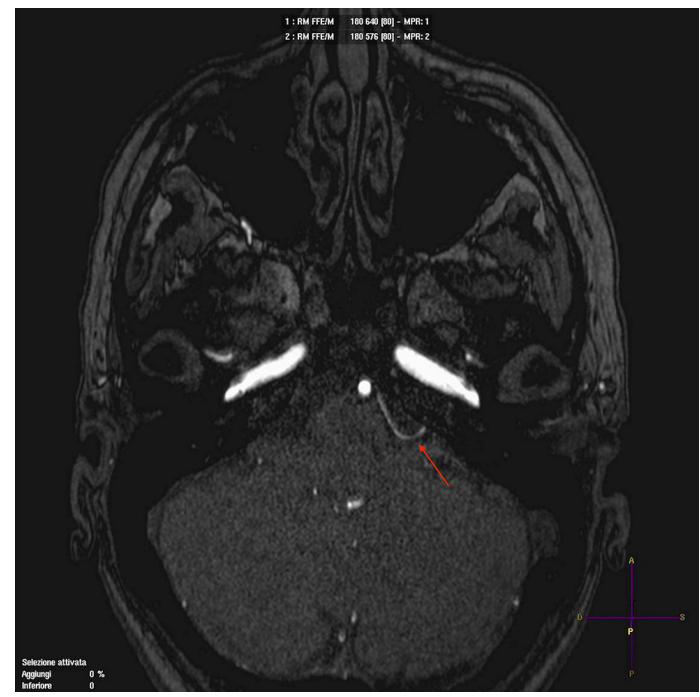

Figure 2 Preoperative 3T time-of-flight MRI angiography sequence. Red arrow: anterior inferior cerebellar artery loop site of the neurovascular conflict with the facial nerve.

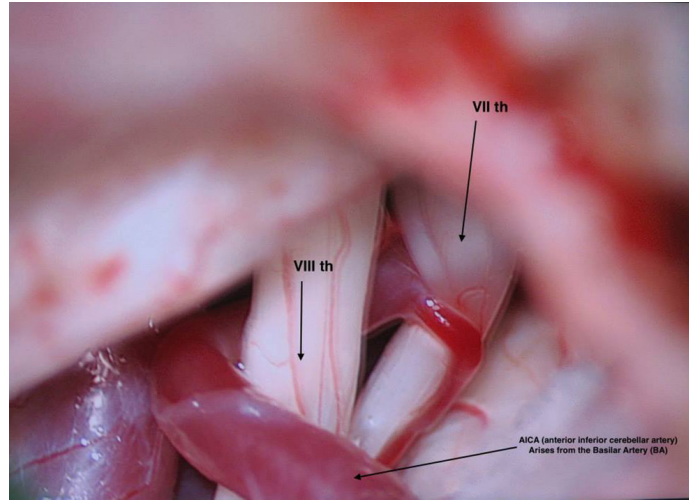

Figure 3 Microscopic view of the longitudinal loop that the small branch from the AICA made around the facial nerve.

patient was resting, causing contraction of all the muscles innervated by the left seventh cranial nerve. MR angiography revealed a neurovascular compression of the left facial nerve by the anterior inferior cerebellar artery (AICA) (figures 1 and 2). The patient was taken to surgery and a microvascular decompression through a retrosigmoid approach was performed. Facial nerve function monitoring was conducted intraoperatively.

The spasm was caused by a vascular loop from a small branch of the AICA between the facial nerve and the vestibulocochlear nerves, causing a longitudinal impression and stretching of the left facial nerve (figure 3). The offending vessel was moved away from the site and the decompression

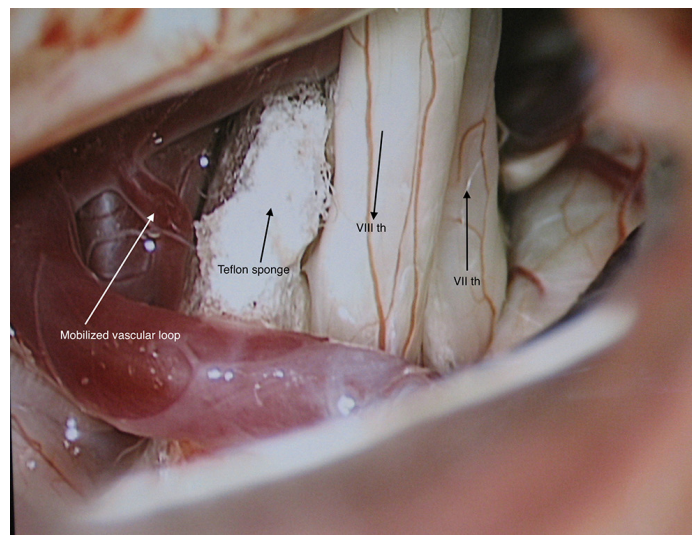

Figure 4 Microscopic view after the microvascular decompression with Teflon sponges placed between the anterior inferior cerebellar artery and the mobilised offending vessel and the acousticofacial bundle. 


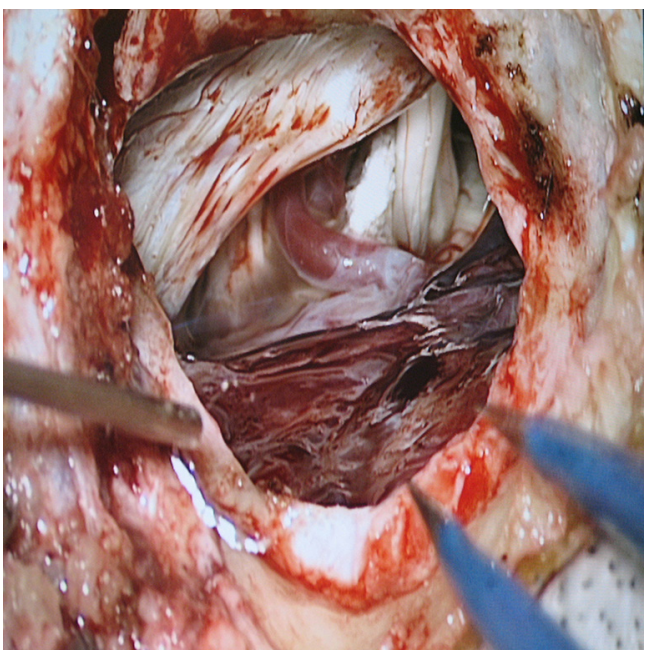

Figure 5 Retrosigmoid craniotomy view after the microvascular decompression with Teflon sponges placed between the anterior inferior cerebellar artery and the mobilised offending vessel, and the acousticofacial bundle.

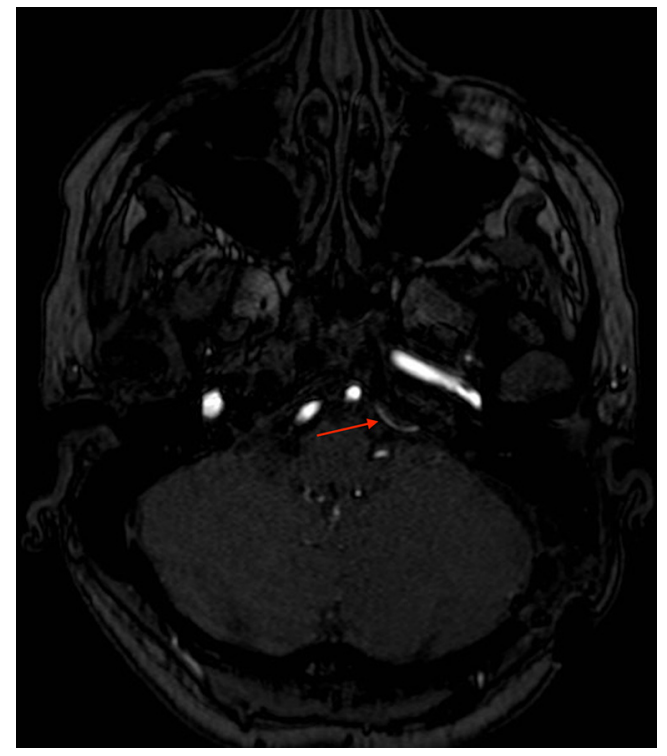

Figure 6 Postoperative 3T time-of-flight MRI angiography sequence. Red arrow: anterior inferior cerebellar artery loop smoothened and lateralised from the root exit zone of the facial nerve.

\section{Learning points}

- Hemifacial spasm is a complex symptom comprising involuntary, painless spasms of the orbicularis oculi muscle that may progress involving all the facial muscles. It usually afflicts middle-aged women and is unilateral, affecting the left more often than the right side.

- The cerebellopontine angle is characterised by the presence of many vascular and neural structures, which are normally in contact with each other without causing symptoms; however, sometimes, this contact may cause disturbances to the patient and becomes symptomatic, leading to the so-called neurovascular compression syndrome, ${ }^{12}$ the symptoms of which depends on the compressed cranial nerves, where the compressing vessel is called an offending vessel. ${ }^{3}$

was secured by inserting Teflon sponges, placed between the offending vessels and the acousticofacial bundle, ensuring that both the Teflon sponge and the offending vessels do not contact the root exit zone nor the transition zone between central and peripheral myelin, which is an anatomical area with increased mechanical vulnerability (figures 4 and 5). The facial spasm disappeared in the immediate postoperative period. MR angiography (figure 6) performed 6 months after surgery confirmed the relapse of the conflict. The patient is free of symptoms.

Contributors PDM wrote the manuscript and is the co-surgeon in charge. RL extracted images and reviewed the manuscript. GR reviewed the manuscript. JM is the surgeon in charge and conducted the study.

Competing interests None declared.

Patient consent Obtained.

Provenance and peer review Not commissioned; externally peer reviewed. (c) BMJ Publishing Group Ltd (unless otherwise stated in the text of the article) 2017. All rights reserved. No commercial use is permitted unless otherwise expressly granted.

\section{REFERENCES}

1 Jannetta PJ. Microsurgery of cranial nerve cross-compression. Clin Neurosurg 1979;26:607-15.

2 Haller S, Etienne L, Kövari E, et al. Imaging of neurovascular compression syndromes: trigeminal neuralgia, hemifacial spasm, vestibular paroxysmia, and glossopharyngeal neuralgia. AJNR Am J Neuroradiol 2016;37:1384-92.

3 Elaini SH, Miyazaki H, Rameh C, et al. Correlation between magnetic resonance imaging and surgical findings in vasculo-neural compression syndrome. $J$ Int $A d v$ Otol 2009:5:1-23.

Copyright 2017 BMJ Publishing Group. All rights reserved. For permission to reuse any of this content visit

http://group.bmj.com/group/rights-licensing/permissions.

BMJ Case Report Fellows may re-use this article for personal use and teaching without any further permission.

Become a Fellow of BMJ Case Reports today and you can:

- Submit as many cases as you like

- Enjoy fast sympathetic peer review and rapid publication of accepted articles

- Access all the published articles

- Re-use any of the published material for personal use and teaching without further permission

For information on Institutional Fellowships contact consortiasales@bmjgroup.com

Visit casereports.bmj.com for more articles like this and to become a Fellow 